\title{
Shock Wave Therapy for Wound Healing and Scar Treatment
}

Peter Moortgat, Mieke Anthonissen, Ulrike Van Daele, Jill Meirte, Tine Vanhullebusch, and Koen Maertens

\section{Contents}

55.1 Working Mechanism of SWT in Relation to Skin Defects - 486

55.2 SWT Dose Effect Relationship - 487

55.3 The Effects of Shock Wave Therapy in Soft Tissue Defects -487

55.3.1 The Effects of SWT in Wound Healing - 487

55.3.2 The Effects of SWT in Scar Management - 488

55.4 Conclusion -488

Bibliography - 489 


\section{Background}

To influence the evolution of an excessive scar toward a normal scar, several physical treatments exist to manage hypertrophic scarring. Physical treatments include manual and mechanical massage, physiotherapy, thermal therapy, and shock wave therapy. Manual massage has a wide array of beneficial effects on scars such as drainage of edema, reduction of pain, and pruritus and hydration of the skin [1]. Mechanical massage or vacuum massage uses gentle vacuum suction to lift the skin and to create a skin fold [2]. Since scars have a propensity to retract and create contractures in joints, splinting, taping, and posture stretching play a crucial role in the treatment. Thermal therapy includes high pressure showers, thread-like showers, and high pressure water and aims to mobilize the skin, to improve flexibility and to reduce inflammation, pain, and pruritus. All of these techniques are frequently used; however, there is only little supporting evidence [3].

The ideal non-invasive scar treatment should be safe, well tolerated by patients, have low associated complication rates, is easy to apply, cost-effective, and can be used in an outpatient setting. Shock Wave Therapy (SWT) meets all the aforementioned requirements [4-7]. The application of shock wave therapy in scar management (• Fig. 55.1) is still in its exploration phase; however, there are some interesting findings [3].

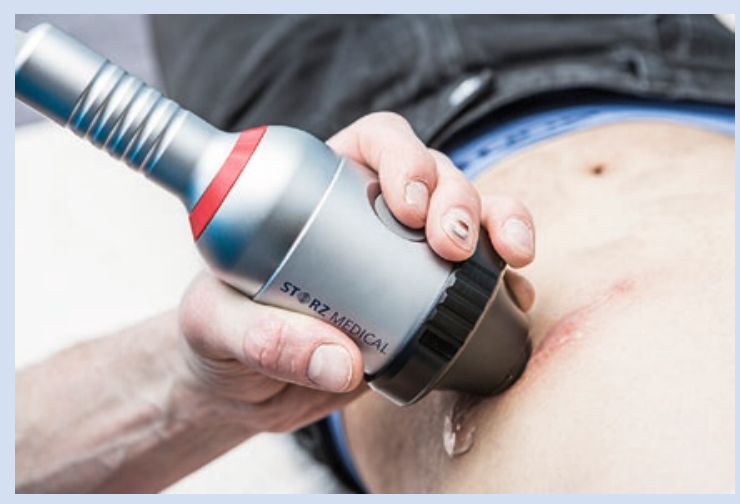

- Fig. 55.1 Shock wave application on a scar

\subsection{Working Mechanism of SWT in Relation to Skin Defects}

SWT converts external mechanical stimuli into biochemical cell reactions (e.g., gene transcription leading to collagen remodeling) in living tissue, supported by mechanotransduction pathways, which result in the activation of numerous cellular events, responsible for the positive effects of SWT on cell metabolism and cell cycle [8]. Moreover, as in some other mechanotherapies applied in clinical practice, the main action of SWT seems to focus on inducing tissue regeneration and matrix remodeling in vivo [9]. Fibroblasts are the major mechanoresponsive cells in connective tissue, and are therefore the main target of SWT [10, 11]. Fibroblasts play a crucial role in remodeling of the extracellular matrix (ECM) by synthesizing and organizing connective tissue components, and there is a strong believe that SWT has a modulating effect on these actions and could therefore be of interest in scar prevention and management.

Sukubo et al. (2015) described the beneficial effects of SWT on macrophage behavior. SWT does not activate resting macrophages and seems to modulate macrophage activity in the inflammatory phase of wound healing. It inhibits the M1 (pro-inflammatory) activation in the initial inflammatory phase and enhances the M2 (anti-inflammatory) activation in the late inflammatory phase [12]. SWT can also regulate inflammation via TLR3 pathway in three phases. In an initiation phase, it induces a pro-inflammatory reaction mediated by cyclophylin A and IL6. There is a suppression of inflammation in the middle phase and in the limitation phase, there is a late anti-inflammatory effect mediated by IL10 [13]. Both findings indicate that SWT, applied in the wound healing stage or in the early stage of scar development, could prevent pathological scarring.

Non-randomized clinical data suggest that SWT is beneficial in terms of improved skin elasticity and revitalizing dermis in females with cellulite [14]. Fibrillar adipose tissue fibrosis looks very similar to dermal scarring [15], so the outcomes of clinical trials investigating cellulite could be transferred to pathological scarring [2]. MR imaging has shown that fibrous septa, visualized in $97 \%$ of the area with cellulite depressions, are markedly thickened in cellulite afflicted areas. Shockwave energy might weaken the fibrous septa, and thus the afflicted skin becomes smoother [14]. There is evolving experimental data suggesting SWT activation pathways in adipose-derived stem cells [14].

Delayed wound healing might be considered as one of the main reasons to develop hypertrophic scars. SWT has repeatedly proven to be effective as a wound-healing modality by decreasing time to full wound closure $[4,5$, $16,17]$. From the mechanobiologic point of view, it has been described that the neoangiogenic capacity could be related to the inhibition of endothelial cell apoptosis, occurring in the very early phase after SWT stimulation (first 3 hours), as an initial response to the mechanical stimulus. More in detail, it seems possible to detect some "preparatory" signals, such as downregulation of the genes involved in cell cycle, adhesion and apoptosis, probably correlated to an upcoming detachment of endothelial junction [9]. After a low-energy SWT treat- 
ment ( 800 shocks, $1 \mathrm{~Hz}, 0.03 \mathrm{~mJ} / \mathrm{mm}^{2}$ ), mRNA expression and protein levels of vascular endothelial growth factor (VEGF) and endothelial nitric oxide synthase (eNOS) were significantly upregulated. Furthermore, the SW therapy enhanced phosphorylation of caveolin- 1 and the expression of HUTS-4 that represents $\beta 1$-integrin activity. These results suggest that caveolin-1 and $\beta 1$-integrin are involved in the SW-induced activation of angiogenic signaling pathways [18].

We can summarize that the overall effect of SWT is an improvement of tissue homeostasis, accompanied by an improvement of the tissue self-healing abilities.

\subsection{SWT Dose Effect Relationship}

For a full treatment outline, the energy flux density (EFD), the number of pulses, the pulse frequency, and the number and interval of treatments are the most relevant parameters [5]. Differences in these parameters can lead to varying outcomes, emphasizing the dose dependency of these mechanotransduction events [9]. Highenergy SWT can suppress cell growth, while low-energy shock waves might enhance cell proliferation [19]. SWT applied with an EFD of $0.01-0.03 \mathrm{~mJ} / \mathrm{mm}^{2}$ can modulate the inflammatory pathway in which macrophages are involved [12], and with an EFD of $0.08 \mathrm{~mJ} / \mathrm{mm}^{2}$ SWT can regulate inflammation via the TLR3 pathway. The EFD for soft tissue indications is typically in the range of $0.08-0.25 \mathrm{~mJ} / \mathrm{mm}^{2}$ [4], while scars and fibrosis are treated with an EFD ranging between 0.15 and $0.33 \mathrm{~mJ} / \mathrm{mm}^{2}$. SWT settings of $0.22 \mathrm{~mJ} / \mathrm{mm}^{2}$ and 1000 pulses seem to be ideal for fibroblast viability and growth [20]. Fibroblast viability was also influenced by the number of pulses. The higher the number, the more risk for cell destruction [11]. Each cell type seems to be responsive to SWT but probably with different optimal device settings and ranges of mechanical stimulation, thus developing different biochemical effects [8]. A study by Lee et al. showed that the EFD plays an important role in the targeting of specific mechano-signaling pathways, with $0.12 \mathrm{~mJ} / \mathrm{mm}^{2}$ being the optimal dose for activating the mTOR-FAK pathway [21] and $0.10 \mathrm{~mJ} / \mathrm{mm}^{2}$ showed the best results for inhibiting TGF- $\beta 1 /$ Smad pathway [22] (• Table 55.1).

\subsection{The Effects of Shock Wave Therapy in Soft Tissue Defects}

\subsubsection{The Effects of SWT in Wound Healing}

Wound healing after SWT is characterized by an upregulation of the angio-active factors such as nitric oxide (NO) and vascular endothelial growth factor (VEGF) leading to induced angiogenesis [17], vasodilatation, increase in vascular and capillary density, and increased local blood flow. NO and VEGF are extremely important, both in early stage and late stage healing $[5,7,9$, $11,17]$. It has been suggested that an aspect of the early gene response of endothelial cells to SWT is characterized by a decreased apoptosis and stimulation of the extracellular matrix metabolism [5, 9]. SWT will lead to reduced tissue necrosis in wound healing by increasing cellular proliferation and procollagen production $[11,23]$. In terms of timing, vasodilatation is noticed at an early stage (first 3 days) and neovascularization at late-stage post intervention [17]. In a clinical trial investigating the efficacy of ESWT to heal chronic therapyrefractory ulcers, the underlying molecular mechanisms were also studied in vitro [24]. Fibroblasts reorganized in a radial and star-shaped clustered manner and had large "stress" fibers. Cluster formation of fibroblasts was dose dependent, meaning that more applications lead to higher clustering. Shock waves also induce upregulation of 67 genes for keratinocytes and 652 genes for fibroblasts, suggesting that SWT mainly targets fibroblasts [24]. The upregulation of Vimentin on mRNA level leading to a visible reorganization of the cytoskeleton provided yet another proof for mechanotransduction as working mechanism for this intervention.

Besides "general wound healing," SWT has specifically been proven effective in burns. First, SWT applied upon donor site healing burn wounds shows a significantly shorter time to complete epithelialization [25]. Second, burn area perfusion has been evaluated with Laser Doppler Imaging before and after SWT and showed a significantly increased perfusion after extracorporeal shockwave therapy treatment [26]. The review of Antonic et al. suggested that SWT may decrease the need for surgical intervention and associated morbidities in patients with severely deep partial- or full-thickness

- Table 55.1 Suggested SWT settings for electro-hydraulic devices when treating wounds or scars

\begin{tabular}{|l|l|l|l|l|l|}
\hline & Energy flux density & Number of pulses & $\begin{array}{l}\text { Pulse } \\
\text { frequency }\end{array}$ & $\begin{array}{l}\text { Treatment } \\
\text { interval }\end{array}$ \\
\hline SWT for wound healing & $0.03-0.20 \mathrm{~mJ} / \mathrm{mm}^{2}$ & $500-1000$ & $4-6 \mathrm{~Hz}$ & $1 \times$ per week & $1-3$ \\
\hline SWT for scar treatment & $0.15-0.33 \mathrm{~mJ} / \mathrm{mm}^{2}$ & $800-1500$ & $4-6 \mathrm{~Hz}$ & $1 \times$ per week & $8-12$ \\
\hline
\end{tabular}


- Fig. $\mathbf{5 5 . 2}$ Cascade of wound-healing processes after SWT

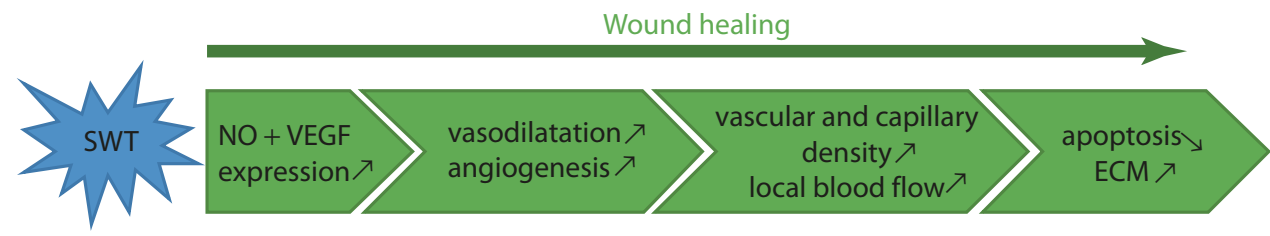

burns [4]. Joo et al. demonstrated that ESWT significantly reduced burn scar pruritus severity and activities-of-daily-living disturbances compared to a control group who received sham treatment. The EFD ranged between 0.05 and $0.20 \mathrm{~mJ} / \mathrm{mm}^{2}$, which seemed useful for pruritus in burn scars [27]. The authors hypothesized that ESWT targeted "neurogenic inflammation," which is an inflammation caused by the release of substances (e.g., SP and CGRP) from primary sensory nerve endings. Nerve fiber loss and the depletion of neuropeptides might decrease inflammation, and thus may decrease itch [28]. A recent meta-analysis showed that ESWT had better therapeutic outcomes on acute and chronic soft tissue wounds when compared to Conventional Wound Therapy (CWT) [29]. The meta-analysis showed that ESWT statistically significantly increased the healing rate of acute and chronic soft tissue wounds 2.73-fold (odds ratio, $\mathrm{OR}=3.73,95 \%$ confidence interval, $\mathrm{CI}$ : 2.30-6.04, $P<0.001)$ and improved wound-healing area percentage by $30.45 \%$ (Standardized Mean Difference $(\mathrm{SMD})=30.45 ; 95 \%$ CI: 23.79-37.12; $P<0.001)$. ESWT reduced wound-healing time by 3 days $(\mathrm{SMD}=-2.86$, 95\% CI:-3.78 to $-1.95, P<0.001)$ for acute soft tissue wounds and 19 days (SMD $=-19.11,95 \% \mathrm{CI}:-23.74$ to $-14.47, P<0.001)$ for chronic soft tissue wounds and the risk of wound infection by $53 \%(\mathrm{OR}=0.47$, 95\% CI: $0.24-0.92, P=0.03$ ) when compared to CWT alone. Serious adverse effects were not reported [29] (• Fig. 55.2).

\subsubsection{The Effects of SWT in Scar Management}

Fibrous tissue can be reduced by SWT (at the origin) during wound healing processes, but it can also be remodeled in a second phase of scar formation. Primary data show that height, pliability, vascularity, and pigmentation, all relevant scar parameters, show improvement after SWT $[6,30]$. The change in these physical and physiological parameters will probably lead to amelioration in function, which is, for example, demonstrated by an increase of passive ROM reported in a study on retracting hand scars [30]. Subjective pain measures also show a decrease in pain at the scar site after SWT [6, 30].

On a histopathological level, the effects of SWT on fibrosis are plural. A downregulation of alphaSMA expression, myofibroblast phenotype, TGF- $\beta 1$ expression, fibronectin, and collagen type I are measured. A significant increase in dermal fibroblast-like phenotype with low contractility and high migratory ability, small vessel density and precursors of extracellular matrix components, probably leads to new and thinner collagen fascicles and parallel orientation to the dermo-epidermal junction [30-32]. Synergistic alterations in pro- and anti-fibrotic proteins (TGF- $\beta 1$ and MMP-2, respectively) suggest a reduced capsule formation after silicone implantation [33]. One study compared ESWT to triamcinolone injections for the treatment of keloids. ESWT showed comparable functional outcome, together with comparable total sum of scores for POSAS patient scale and POSAS observer scale clinically. A significant reduction in collagen fibers and increased expression of MMP-13 degrading enzyme could be seen when compared to intralesional steroid injection [34]. Zhao et al. demonstrated positive results on planimetric scar characteristics and inhibition of TGF- $\beta 1 /$ Smad signaling pathway with Radial Extracorporeal Shockwave Therapy [22], as well as decreased Scar Elevation Index, fibroblast density, and $\alpha$-smooth-muscle-actin expression in hypertrophic scar tissues of a rabbit model [35].

The most promising results in the research for the effects of SWT on scars were presented as preliminary data of an ongoing randomized placebo controlled trial investigating the effects of SWT in the management of hypertrophic scars. The results of the objective assessments showed a statistically significant better performance of the intervention group for elasticity assessed with cutometry [36] (• Table 55.2).

\subsection{Conclusion}

All the presented findings are fundamental knowledge for further investigation of SWT to reduce the fibrous component in regenerating and remodeling tissues. The dose dependency of the treatment effects remains understudied. Energy Flux Density, number of shocks, shock frequency, and treatment interval and number are all important parameters in the choice for the most suitable device settings, in relation to the indication. Future studies should include these parameters as covariates to determine the right-specific approach for each scar. The full potential of SWT in wound healing, scar treatment, and cellulite certainly needs further unraveling. 
Table 55.2 SWT effects on wound healing, scar formation + remodeling, and cellulite

\begin{tabular}{|c|c|c|}
\hline Effect of SWT on & Changes in histopathological parameters & Physical and physiological changes \\
\hline Wound healing & $\begin{array}{l}\text { Stimulation of the ECM metabolism } \\
\text { Upregulation of cell-cycle regulatory genes } \\
\text { Reorganization of the cytoskeleton }\end{array}$ & $\begin{array}{l}\text { Angiogenesis } \\
\text { Vasodilatation } \\
\text { Increase in vascular and capillary density } \\
\text { Increase in local blood flow } \\
\text { Decrease in apoptosis } \\
\text { Reduction of tissue necrosis }\end{array}$ \\
\hline Burn wound healing & & $\begin{array}{l}\text { Shorter epithelialization time } \\
\text { Increase in perfusion }\end{array}$ \\
\hline $\begin{array}{l}\text { Scar formation and } \\
\text { remodeling }\end{array}$ & $\begin{array}{l}\text { Downregulation on alpha-SMA expression, } \\
\text { myofibroblast phenotype, TGF- } \beta 1 \text { expression, and } \\
\text { fibronectin } \\
\text { Decrease in collagen type I } \\
\text { Upregulation dermal fibroblast-like phenotype } \\
\text { Increase small vessel density (ratio type I/type III } \\
\text { collagen) } \\
\text { Increase in precursors of ECM components } \\
\text { Synergistic alterations in pro- and anti-fibrotic } \\
\text { proteins }\end{array}$ & $\begin{array}{l}\text { Formation of new and thinner collagen fascicles } \\
\text { Reduced capsule formation } \\
\text { Decrease in height } \\
\text { Increased pliability } \\
\text { Normalization of vascularity and pigmentation } \\
\text { Amelioration of function (range of motion) } \\
\text { Decrease in pain }\end{array}$ \\
\hline Cellulite & $\begin{array}{l}\text { Decrease of serum malondialdehyde and plasma } \\
\text { protein carbonyls } \\
\text { Release of lipid peroxidation products influence } \\
\text { adipose-derived stem cells }\end{array}$ & $\begin{array}{l}\text { Weakening of the fibrous septae } \\
\text { Smoothening of skin }\end{array}$ \\
\hline
\end{tabular}

\section{- Take-Home Messages}

- SWT meets all the requirements for the ideal noninvasive scar treatment.

- Mechanotransduction is the working mechanism behind SWT.

- SWT induces tissue regeneration and remodeling in vivo.

- Inflammation can be modulated by SWT.

- Low-energy SWT induces cell proliferation, while high-energy SWT suppresses cell growth.

- SWT can decrease time to full wound closure and reduces the risk for tissue necrosis.

- SWT may improve scar elasticity, which will probably lead to amelioration of function.

- There is a high dose-effect relationship when treating soft tissue defects with SWT.

\section{Bibliography}

1. Anthonissen M, Daly D, Janssens T, Van den Kerckhove E. The effects of conservative treatments on burn scars: a systematic review. Manuscr. Submitt. Publ. 2015.

2. Moortgat P, Anthonissen M, Meirte J, et al. The physical and physiological effects of vacuum massage on the different skin layers: a current status of the literature. Burn Trauma. 2016; 4:34.

3. Middelkoop E, Monstrey S, Téot L, Vranckx J. Scar management: practical guidelines. Belgium: Elsene; 2011.
4. Antonic V, Mittermayr R, Schaden W, Stojadinovic A. Evidence supporting extracorporeal shock wave therapy for acute and chronic soft tissue wounds. Wounds Compend Clin Res Pract. 2011;23:204-15.

5. Mittermayr R, Antonic V, Hartinger J, Kaufmann H, Redl H, Téot L, Stojadinovic A, Schaden W. Extracorporeal shock wave therapy (ESWT) for wound healing: technology, mechanisms, and clinical efficacy. Wound Repair Regen. 2012;20:456-65.

6. Fioramonti P, Cigna E, Onesti MG, Fino P, Fallico N, Scuderi N. Extracorporeal shock wave therapy for the management of burn scars. Dermatol Surg. 2012;38:778-82.

7. Romeo P, Lavanga V, Pagani D, Sansone V. Extracorporeal shock wave therapy in musculoskeletal disorders: a review. Med Princ Pract. 2014;23:7-13.

8. Huang C, Holfeld J, Schaden W, Orgill D, Ogawa R. Mechanotherapy: revisiting physical therapy and recruiting mechanobiology for a new era in medicine. Trends Mol Med. 2013;19: 555-64.

9. d'Agostino MC, Craig K, Tibalt E, Respizzi S. Shock wave as biological therapeutic tool: from mechanical stimulation to recovery and healing, through mechanotransduction. Int J Surg. 2015;24:147-53.

10. Wang JH-C, Thampatty BP, Lin J-S, Im H-J. Mechanoregulation of gene expression in fibroblasts. Gene. 2007;391:1-15.

11. Frairia R, Berta L. Biological effects of extracorporeal shock waves on fibroblasts. A review. Muscles Ligaments Tendons J. 2011;1:137-46.

12. Sukubo NG, Tibalt E, Respizzi S, Locati M, d'Agostino MC. Effect of shock waves on macrophages: a possible role in tissue regeneration and remodeling. Int J Surg. 2015;24:124-30.

13. Holfeld J, Tepeköylü C, Kozaryn R, Urbschat A, Zacharowski K, Grimm M, Paulus P. Shockwave therapy differentially stimulates endothelial cells: implications on the control of inflammation via toll-like receptor 3. Inflammation. 2014;37:65-70. 
14. Knobloch K, Joest B, Krämer R, Vogt PM. Cellulite and focused extracorporeal shockwave therapy for non-invasive body contouring: a randomized trial. Dermatol Ther (Heidelb). 2013;3:143-55.

15. Kruglikov I. The pathophysiology of cellulite: can the puzzle eventually be solved? J Cosmet Dermatol Sci Appl. 2012;02:1-7.

16. Schaden W, Thiele R, Kölpl C, Pusch M, Nissan A, Attinger CE, Maniscalco-Theberge ME, Peoples GE, Elster EA, Stojadinovic A. Shockwave therapy for acute and chronic soft tissue wounds: a phase II trial. J Surg Res. 2007;137:246.

17. Yan X, Zeng B, Chai Y, Luo C, Li X. Improvement of blood flow, expression of nitric oxide, and vascular endothelial growth factor by low-energy shockwave therapy in random-pattern skin flap model. Ann Plast Surg. 2008;61:646-53.

18. Hatanaka K, Ito K, Shindo T, Kagaya Y, Ogata T, Eguchi K, Kurosawa R, Shimokawa H. Molecular mechanisms of the angiogenic effects of low-energy shock wave therapy: roles of mechanotransduction. Am J Physiol Cell Physiol. 2016;311:378-85.

19. Cai Z, Falkensammer F, Andrukhov O, Chen J, Mittermayr R, Rausch-Fan X. Effects of shock waves on expression of IL-6, IL-8, MCP-1, and TNF- $\alpha$ expression by human periodontal ligament fibroblasts: an in vitro study. Med Sci Monit. 2016;22: 914-21.

20. Berta L, Fazzari A, Ficco AM, Enrica PM, Catalano MG, Frairia R. Extracorporeal shock waves enhance normal fibroblast proliferation in vitro and activate mRNA expression for TGF-betal and for collagen types I and III. Acta Orthop. 2009;80:612-7.

21. Lee F-Y, Zhen Y-Y, Yuen C-M, Fan R, Chen Y-T, Sheu J-J, Chen Y-L, Wang C-J, Sun C-K, Yip H-K. The mTOR-FAK mechanotransduction signaling axis for focal adhesion maturation and cell proliferation. Am J Transl Res. 2017;9:1603-17.

22. Zhao J-C, Zhang B-R, Shi K, Wang J, Yu Q-H, Yu J-A. Lower energy radial shock wave therapy improves characteristics of hypertrophic scar in a rabbit ear model. Exp Ther Med. 2018;15:933-9.

23. Kuo Y-R, Wu W-S, Hsieh Y-L, Wang F-S, Wang C-T, Chiang Y-C, Wang C-J. Extracorporeal shock wave enhanced extended skin flap tissue survival via increase of topical blood perfusion and associated with suppression of tissue pro-inflammation. J Surg Res. 2007;143:385-92.

24. Aschermann I, Noor S, Venturelli S, Sinnberg T, Mnich CD, Busch C. Extracorporal shock waves activate migration, proliferation and inflammatory pathways in fibroblasts and keratinocytes, and improve wound healing in an open-label, single-arm study in patients with therapy-refractory chronic leg ulcers. Cell Physiol Biochem. 2017;41:890-906.

25. Ottomann C, Stojadinovic A, Lavin PT, Gannon FH, Heggeness MH, Thiele R, Schaden W, Hartmann B. Prospective random- ized phase II trial of accelerated reepithelialization of superficial second-degree burn wounds using extracorporeal shock wave therapy. Ann Surg. 2012;255:23-9.

26. Arnó A, García O, Hernán I, Sancho J, Acosta A, Barret JP. Extracorporeal shock waves, a new non-surgical method to treat severe burns. Burns. 2010;36:844-9.

27. Joo SY, Cho YS, Seo CH. The clinical utility of extracorporeal shock wave therapy for burn pruritus: a prospective, randomized, single-blind study. Burns. 2018;44:612-9.

28. Hausdorf J, Lemmens MAM, Kaplan S, Marangoz C, Milz S, Odaci E, Korr H, Schmitz C, Maier M. Extracorporeal shockwave application to the distal femur of rabbits diminishes the number of neurons immunoreactive for substance $\mathrm{P}$ in dorsal root ganglia L5. Brain Res. 2008;1207:96-101.

29. Zhang L, Fu X, Chen S, Zhao Z, Schmitz C, Weng C. Efficacy and safety of extracorporeal shock wave therapy for acute and chronic soft tissue wounds: a systematic review and meta-analysis. Int Wound J. 2018;15:590-9.

30. Saggini R, Saggini A, Spagnoli AM, Dodaj I, Cigna E, Maruccia M, Soda G, Bellomo RG, Scuderi N. Extracorporeal shock wave therapy: an emerging treatment modality for retracting scars of the hands. Ultrasound Med Biol. 2016;42:185-95.

31. Rinella L, Marano F, Berta L, Bosco O, Fraccalvieri M, Fortunati N, Frairia R, Catalano MG. Extracorporeal shock waves modulate myofibroblast differentiation of adipose-derived stem cells. Wound Repair Regen. 2016;24:275-86.

32. Cui HS, Hong AR, Kim J-B, Yu JH, Cho YS, Joo SY, Seo $\mathrm{CH}$. Extracorporeal shock wave therapy alters the expression of fibrosis-related molecules in fibroblast derived from human hypertrophic scar. Int J Mol Sci. 2018; https://doi.org/10.3390/ ijms19010124.

33. Fischer S, Mueller W, Schulte M, Kiefer J, Hirche C, Heimer S, Köllensperger E, Germann G, Reichenberger MA. Multiple extracorporeal shock wave therapy degrades capsular fibrosis after insertion of silicone implants. Ultrasound Med Biol. 2015;41:781-9.

34. Wang C-J, Ko J-Y, Chou W-Y, Cheng J-H, Kuo Y-R. Extracorporeal shockwave therapy for treatment of keloid scars. Wound Repair Regen. 2018;26:69-76.

35. Zhao J-C, Zhang B-R, Hong L, Shi K, Wu W-W, Yu J-A. Extracorporeal shock wave therapy with low-energy flux density inhibits hypertrophic scar formation in an animal model. Int $\mathbf{J}$ Mol Med. 2018;41:1931-8.

36. Moortgat P, Meirte J, Anthonissen M, Lafaire C, De Cuyper L, Maertens K. Extracorporeal shockwave therapy for management of hypertrophic scars: preliminary results of a randomised placebo controlled trial. Ann Burns Fire Disasters. 2015; https:// doi.org/10.13140/RG.2.1.2699.3125.

Open Access This chapter is licensed under the terms of the Creative Commons Attribution 4.0 International License (http://creativecommons. org/licenses/by/4.0/), which permits use, sharing, adaptation, distribution and reproduction in any medium or format, as long as you give appropriate credit to the original author(s) and the source, provide a link to the Creative Commons license and indicate if changes were made.

The images or other third party material in this chapter are included in the chapter's Creative Commons license, unless indicated otherwise in a credit line to the material. If material is not included in the chapter's Creative Commons license and your intended use is not permitted by statutory regulation or exceeds the permitted use, you will need to obtain permission directly from the copyright holder. 